\title{
A Planning and Management Infrastructure for Complex Distributed Organizations
}

\author{
George L. Kovács
}

Computer and Automation Research Institute (www.sztaki.hu)

Kende u. 13, H-1111 Budapest, Hungary,gvorgv.kovacs@sztaki.hu

\section{Paolo Paganelli}

Gruppo Formula Spa. (www.gformula.com), Via Matteotti, 5. I - 40055

Villanova di Castenaso (BO), Italy, paolo.paganelli@formula.it

\begin{abstract}
The objective of our work is to provide a web-based, software supported planning and management infrastructure for complex, distributed organizations working on large scale engineering projects. Such projects are characterized by huge investments in both materials and human resources and by concurrent, disparate activities - manufacturing, design and services as well. These type of projects are rarely carried out within the scope of a single organization, or at least several, distributed parts of the organization and/or subcontractor small and medium enterprises (SME) are often involved, too.
\end{abstract}

Key words: management, complex enterprises, web-based, infrastructure, engineering

\section{INTRODUCTION}

In the following the main ideas (problems and suggested solutions) of a European joint project are going to be detailed. The WHALES (Weblinking Heterogeneous Applications for Large-scale Engineering and Services) project started in March, 2000 and it has Italian, German, Portuguese and Hungarian participants. In the following to distinguish between the project itself and projects managed by WHALES, the word project will be used for the managed projects, and the running project itself will be called the WHALES system, or simply the system.

The objective of our system (under development) is to provide a planning and management infrastructure for complex distributed organizations working on large scale engineering projects, characterized by

The original version of this chapter was revised: The copyright line was incorrect. This has been corrected. The Erratum to this chapter is available at DOI: 10.1007/978-0-387-35492-7_50 
huge investments in both materials and human resources and by concurrent, disparate activities - manufacturing, design and services as well. Managing projects of this kind means dealing with several problems at the same time, as:

- Complexity of scope, in terms of time and resources employed, and variety of activities to be planned, synchronized and monitored;

- Distributed organization, spanning through several companies and involving a multiplicity of actors and competencies;

- One-of-a-kind design, increasing planning complexity, hard to apply product and process standardization;

- Geographic distribution of project activities, sometimes in unprepared or hostile environments;

- Strict time constraints, with complex milestones and dangerous criticalpath dependencies;

- Contingency risks, due to the high planning uncertainty and difficult realignment of activities;

- Revenue-loss risks, due to difficulties in budgeting and high contingency costs.

Such projects are rarely carried out within the scope of a single organization. More often the prime contractor, typically a large company with adequate know-how, references and financial resources to sustain the project, outsources specific components and services to smaller firms through several forms of sub-contracting. This way SMEs are often involved.

For the prime contractor and its major partners, winning a project represents a demanding and risky activity in itself. The best available technical and management skills are required to present competitive offers in a world-scale market where ability to perform, rapid implementation and acceptable cost are at least as important as background expertise and technical quality. The goal of this system is to try to answer the above challenges even if there are the following problems, too:

- High direct and indirect costs of basic resources;

- Complex and hierarchical organizations grown up in better times of unchallenged and stable demands (e.g., markets protected by local governments);

- Low operative margins, putting short-term activities and contingency management ahead of technology and business process improvements;

- Cultural and organizational obstacles to apply "virtual enterprise" partnership models;

- Low flexibility that, burdened with complexity, makes it almost impossible to prepare reliable plans and project budgets. 


\section{EXPECTED RESULTS - BENEFITS}

As an alternative to massive restructuring, which would entail significant losses in terms of employment, technical potential and historical background, we intend to enhance the project planning and deployment capabilities of the involved firms, thanks to a software infrastructure producing the following measurable results on the end-users business:

\subsection{Improved planning and budgeting}

These will be measured in percentage of successful bids, and in planned vs. actual costs/duration, etc. and will be achieved by means of designing and implementing several subsystems, and taking into consideration several important factors at the same time, as:

- A planning and financial analysis system for bid preparation (tendering): projects managed by our system have to go over a hard preliminary competition, commonly called "tendering". The price, the deadlines, the technical specifications have to be given in a bid, so a poorly calculated bid can result winning the order but failing the profit and the delivery terms;

- Considering the whole scope of project activities (including subcontracted ones, as well as needed materials, machinery and human resources at all project sites) when taking project timing and allocation decisions;

- All decisions will be based on updated and consistent information about running activities and availability of resources, on aggregating and normalizing data from heterogeneous applications and different functional domains both inside the company and across the consortium network - using appropriate DSS (Decision Support Systems);

- Analyzing and comparing alternative scenarios, generated through alternatives on a full scale project model, and evaluated and compared by means of advanced on-line analytical processing tools - using appropriate simulation and DSS tools;

\subsection{Improved monitoring, cost and risk assessment}

These will be measured in manpower/assets utilization, in reduction of "idle" time (waiting for unfinished activities), etc. and they will be achieved by means of:

- On-line access to the current status of project activities (the resources consumed at all project sites, the quantifiable results and costs borne, and any other indicators relevant to project progress evaluation and current risk assessment); 
- Real-time notification of events and conditions constituting potential failure sources to the appropriate actors in the project network, according to rules and criteria set case by case (e.g., maximum delay on a critical path activity);

- Automatic update of the project plan, highlighting deviations between actual and planned activities, their impact on related tasks and milestones, and corrections required to meet the project objectives.

\subsection{Effective contingency management}

This is measurable by the percentage of "perfect orders", i.e. orders delivered according to original request, and by the reduction in number of cancelled or re-negotiated orders, - and will be gained by:

- Pro-active risk analysis in the project planning phase, where alternative solutions are compared considering both internal factors (e.g. strict time-dependencies) and external factors (e.g. casual distribution of machine failure or manpower shortage at project sites);

- Re-planning in the project deployment phase in reaction to alerts and deviations notified by monitoring functions, selecting backup options on the basis of cost, perturbations on running activities, need for renegotiation of already set plans, etc.;

- Alignment of the whole project plan to changes on re-planned activities, promptly updating all project sites and management levels, and tracking of project revisions for costs evaluation and statistical risk analysis.

\subsection{Higher flexibility and efficiency}

The best measures for them are the increase in bids processed by the same organization, the reduction of bid preparation cycle time and the profit margins by order and project unit. These can be approached by:

- Ability to respond quickly to customers' requests for proposals and requests for changes by involving the appropriate technical and management skills at all project sites;

- Better exploitation of the network resources, thanks to a decisionsupport environment which is aware of co-operation possibilities (e.g., roles to be fulfilled in a project under planning) and available partners' skills and capacities;

- Prompt negotiation of planning and re-planning options, by means of a communication infrastructure that circulates decisions and events between the appropriate actors, crossing companies and organizational units boundaries; 


\section{SYSTEM GOALS - TASKS TO BE SOLVED}

To achieve the above improvements requires dealing with different enterprise functions and information sources, supported by heterogeneous and poorly integrated software applications, as:

- Enterprise Resources Planning systems (ERP) (as SAP, Baan, etc.) represent the companies' administration backbone, and provide basic transactions for bids and contracts management, job order stages and costs reporting, billing and invoicing;

- Production Planning and Control (PPC) and Warehousing systems, often sold as ERP components, support materials management and long- to short-term production planning;

- Project planning tools provide graphical editing of GANNT and PERT project diagrams, along with on-line display of resources workload and activities timing;

- Human Resources (HR) packages support company organization management, identifying key project roles, skills and positions, as well as project personnel costs and time-tables.

None of these systems alone covers the full spectrum of project management requirements, that in complex organizations range from financial planning and cost analysis to human resources recruiting and assignment, to procurement and allocation of manufacturing resources and materials. Moreover, none of these systems provides a data and communication infrastructure for the whole project network, i.e., the multisite, multi-company organization created to fulfil specific project objectives. As a temporary and goal-oriented structure, although it can last years and absorb large turnover shares, the project network presents typical "virtual enterprise" properties that make it impossible to map it on traditional, enterprise-centric information systems.

In response to these requirements, the WHALES system will pursue two main objectives, which should be solved by the system software:

- To design and develop a set of software components supporting integrated planning, deployment and monitoring of large projects in multi-site, multi-enterprise organizations;

- To demonstrate the applicability and benefits of the developed software components through analysis, implementation and experimental usage on different type of pilot business cases presented by different users in different countries spread in Europe.

As an innovative system for project management in complex and distributed organizations, the system shall implement the following general features: 
3.1 Provide a unified and generalized representation of project activities and related artifacts, comprising all material and immaterial work items (e.g., products, knowledge, design documents in different stages) that need to be organized in complex projects (in our test cases: shipbuilding, engineering industry, plant repair and maintenance services).

3.2 Support distributed organization models, crossing hierarchies and company boundaries; to be general and commercially exploitable, the system shall not rely on any pre-defined organization schema, but will support a case-by-case definition of links between companies, organizational units and employees involved in each project.

3.3 Provide a scalable and flexible co-operation environment. The system will provide a project network infrastructure accessible to every node (company or organization unit) independently of its size and information system. It will support nodes and individuals in readjusting their role and interface toward the network (for example to reflect changes in the node internal organization, or to make new resources available to any project).

3.4 Integrate and distribute relevant information across the project network. Data maintained by each node and related to a specific project will be given a generalized representation and shared with the other project participants through a web-based environment according to visibility and consistency rules mirroring the project organization model and management responsibilities.

3.5 Support decision-making in the project ideation, definition and deployment phases. This means to select potential partners on the basis of their past performance, cost and capabilities, to generate detailed plans considering both activities' timing, equipment and materials availability, and to find substitute resources for a running activity, etc.

3.6 Manage and synchronize the flow of decisions and events in the project network. The system will manage the distributed workflow associated to a project e.g. circulating planning proposals among the partners, integrating multiple decision threads in a consistent and transparent fashion, and dispatching monitored exceptions to the responsible actor(s) for contingency management.

3.7 Integrate with local management and planning systems. It means to safeguard the nodes' autonomy and IT investments. The system shall not interfere with node internal procedures and management tools, as ERP, PPC, Human Resources, stand-alone Project Planning and Budgeting packages. Instead, proper interfaces shall be designed for real-time information exchange between these systems and our system network infrastructure. 


\section{INNOVATIVE SYSTEM FEATURES}

The most innovative aspects of our system solution lie in its distributed architecture design, that provides an integrated data and process infrastructure for different companies and actors participating in large projects' planning and execution, at the same time safeguarding each node's autonomy as regards local operations management and information system. These features match key requirements of the so called "virtual enterprise" organizations working on large one-of-a-kind industrial projects, recently highlighted by a survey on European large scale engineering companies carried out in the IV. Framework Programme ([1]).

The main findings of the survey are: lack of data models, communications and workflow infrastructures for project teams "extended" to suppliers and sub-contractors; lack of lifecycle planning, costing and risk assessment tools for complex distributed projects. State-of-the-art software applications offer only partial responses to the above needs, being still too much dependent on specific industrial sectors, organization models or ERP platforms, and approaching project management with a solution- rather than a problem-oriented approach, focused on a specific tool or technology application. Their goal is to optimize a single aspect of project life-cycle management, as:

- ERP packages' Management extensions. ERP systems are adopted as the enterprise backbone for execution functions. World-class packages (e.g., SAP, JDEdwards, Baan) provide project management modules capable to integrate typical ERP functions like job orders management, accounting and purchase, with higher level features like Work Breakdown Structure (WBS) or project profitability analysis.

- Project Management applications include a wide range of software products. Professional project planning and project accounting suites (e.g., SAS, Solomon Software) provide advanced decision support, scheduling and on-line analysis features. Office project applications (e.g., MS Project) provide graph- and table-based editing for manually planned projects, easy to use and integrated with common office tools. Dedicated packages provide a broad range of project management features for specific industrial sectors (e.g., ABT for software development projects, others in many sectors).

- Data Interchange and Workflow infrastructures recently emerged as means for improving efficiency and standardize operations of complex distributed organizations, including engineering networks. On the one side, standards for data and documents interchange (e.g., STEP, EDI) provide the foundations for knowledge sharing and communication of 
engineering and commercial information. On the other side, communication and workflow technologies provide process automation features for real-time electronic business interactions.

WHALES will introduce a significant advance on project management practices supported by state-of-the-art applications, thanks to a flexible architecture integrating project-related data from heterogeneous applications, workflow automation, and decision support functions into a web-based environment. The resulting system is expected to accommodate the needs of project networks independently of the industrial sector, thanks to its general and adaptable design, that comes from features like:

- Distributed project management environment,

- Decentralized architecture and accountability structure,

- Powerful project and network data model,

- Flexible decision-support tools.

The decentralized and flexible system model will safeguard the autonomy and visibility of each network node, independently of its size. This will prevent the constitution of hierarchical project networks, actually dominated by a single, large contractor. Typically this happens when planning and logistics departments of large firms, faced with tasks surpassing their traditional responsibilities, tend to pass part of this complexity onto their suppliers. These are often SMEs, whose resources and commercial strength are insufficient to deal with such demanding scenarios, with consequent problems in terms of competitiveness, losses and high risk on investments.

Concerning the research state of the art, we can identify two main directions pursued in the last years by many projects:

- On the one side, standards and systems are sought for product and process data modeling and interchange, and to support distributed design in concurrent and co-operative engineering environments. This category of projects focuses on the "what", i.e., on the contents specifications for a product or project, rather than on the "how" and "when" that are typical project management concerns. References to some of these projects are in [2 and 3].

- On the other side, virtual enterprises are studied as evolving organisms, investigating environmental, legal and socio-economic conditions for the creation of enterprise networks.

- Considerably less effort has been directed to the analysis of the planning and monitoring problems characterizing such networks, and to how co-operation can be sustained and managed on a daily basis. References to some of these projects are in [4 and 5]. 


\section{SYSTEM TEST CASES AND ARCHITECTURE}

The WHALES results will be demonstrated by four different type of pilot cases in four different European countries:

- Lisnave, an important Portuguese company with a long tradition in shipbuilding and ship-repairing services. It is presently suffering aggressive competition from the far East;

- FATA, a large Italian engineering company, it represents a complex and hard-to-manage business with respect to leaner and faster manufacturing SMEs in the North-East;

- MTS, from Hungary is facing foreign competition with a business organization typical of state-owned companies operating on local, protected markets;

- METZ, a German medium-sized firm delivering customized vehicles and vehicle equipment services. It has to synchronize engineering, manufacturing and procurement activities in a typical one-of-a-kind environment.

The system architecture has been designed to match the project wide application scope, the complexity of technical objectives, the variety and extent of business cases to be analyzed and implemented at pilot users' sites. Each of these topics raise different categories of problems, requiring specific competencies and additional co-ordination along with conventional project management and software development activities. The work to be undertaken has been subdivided into two basic thematic areas. See Fig. 1. for all important relationships.

The two basic thematic areas (1. and 2. in Fig. 1.) in the system development are the following:

\subsection{Network Architecture \& Software Components}

The project main body consists of five technical parts devoted to the study and development of the ICT architecture and software components that are going to support the system network organization model. Each part includes the fundamental activities of a quality-based software development process: requirements, analysis and design, implementation, test and deployment. A sixth part provides a common development infrastructure for the teams dealing with: methodology and tools to be used, selection of existing re-usable components, co-ordination of joint developments, maintenance of a technical data repository, configuration and change management. 


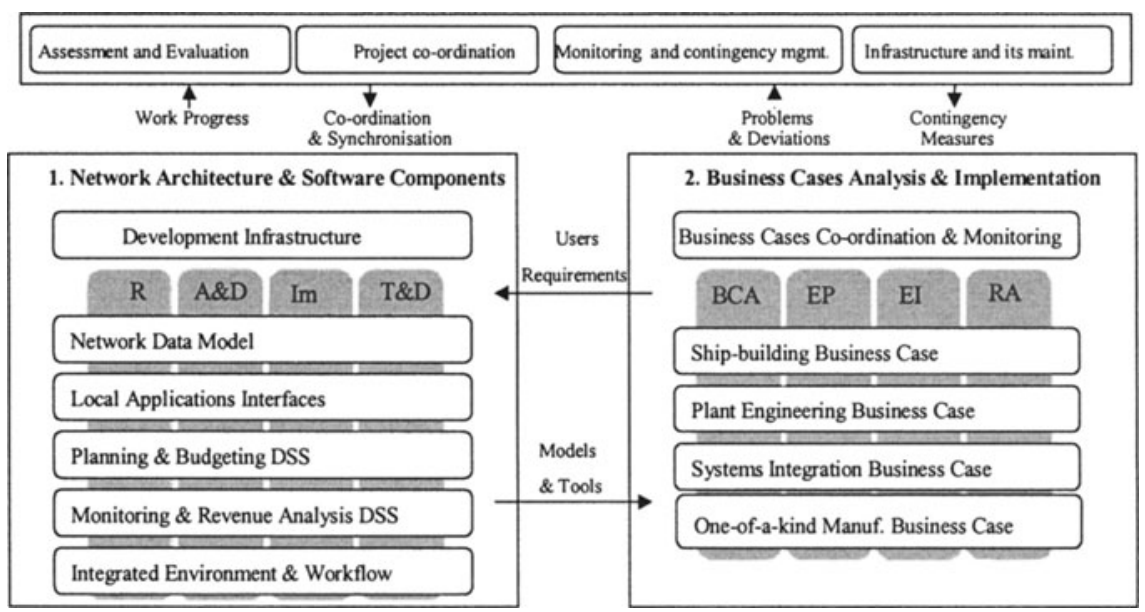

R: Requirements - A\&D: Analysis and Design - Im: Implementation, T\&D: Test and Deployment, BCA: Business Cases Analysis - EP: Experiment Preparation EI: Experiment Implementation, RA: Results'Assessment.

Figure 1: system architecture

\subsection{Business Cases Analysis \& Implementation}

In parallel with technical developments, the proposed organization model and tools are introduced and applied on four business cases proposed by users in different industrial sectors in different countries. Each business case consists of the fundamental activities of business case analysis, experiment selection and preparation, experiment implementation and results assessment. All business cases will apply common methodologies, metrics and best practices to ensure uniformity, comparison and joint evaluation of all results produced.

In addition due to the complexity of the tasks a solid Project Management is necessary to take care of monitoring and accounting of project activities, risk assessment and contingency management and project infrastructure maintenance.

The main relationships of the thematic areas (and of all other important parts) are represented by arrows in Fig. 1:

1) User requirements produced in business cases analysis are a necessary input to software analysis and design specifications.

2) Models specifications and software tools produced in the technical segment are necessary for experiments preparation and implementation of all business cases. 


\section{CONCLUSIONS}

The WHALES system is designed and implemented by a European team of four countries. The work started with defining common tools and principles to avoid any misunderstanding. A well organized management takes care of all harmonization problems, and four test cases will prove the applicability of the results. The results will provide a web-based planning and management infrastructure for complex distributed organizations working on large scale engineering projects, characterized by huge investments in both materials and human resources and by concurrent, disparate activities - manufacturing, design and services as well.

\section{REFERENCES}

1. EP 20876 ELSEWISE (www.cordis.lu)

2. EP 20377 OPAL (www.cordis.lu)

3. EP 20408 VEGA (www.cordis.lu)

4. IMS GLOBEMAN21 (www.ims.org)

5. EP 26854 VIVE (www.cordis.lu)

\section{BIOGRAPHIES}

George L. Kovács got his Dr.Techn. degree (Ph.D.) at the Technical University of Budapest,. 1976. and he is Prof. at the same university since 1995. In 1997 he got the Dr. of the Academy degree from the Hungarian Academy of Sciences (HAS). He is with the Computer and Automation Research Institute of HAS since 1966, recently head of the CIM Research Laboratory. Visiting researcher in the USA, Soviet Union, West Germany. Visiting professor in Mexico and at the University of Trento, Italy. Author of more than 250 scientific publications. Member of several Hungarian and international scientific organizations, including IEEE, IFAC and IFIP. Project manager of several Hungarian and international R\&D projects.

Paolo Paganelli graduated in Electronic Engineering at the University of Bologna in 1991. Research assistant at the University of Modena (19921994). From 1994 to 1997 he worked at Democenter, in the R\&D department as technical manager in different ESPRIT projects. In 1997 joined Gruppo Formula S.p.A., as senior analyst involved in the design of Formula's next generation ERP software. He is now Formula's Product Manager for Supply Chain Management solutions. He is the initiator and project manager of the ESPRIT projects FLUENT (Flow-oriented Logistics Upgrade for Enterprise Networks) and WHALES. He published around 30 papers, including presentations at international conferences. 